\title{
Psychometric evaluation of the Arabic version of the higher education inventory scale for nursing students
}

\author{
Dina Masha'al ${ }^{1}$, Audai A. Hayajneh ${ }^{2^{*}}$ (D) and Loai Issa Tawalbeh ${ }^{3}$
}

\begin{abstract}
Background: Studies in the literature have relied on a single instrument to assess stress levels and sources among nursing students in Jordan and in other Arab countries. Thus, there is a need to develop Arabic versions of psychometrically validated instruments for evaluating a wider range of aspects related to stress and stressors. The Higher Education Stress Inventory (HESI) is an instrument used to assess various aspects of stress and stressors related to higher education in different educational settings and among different student populations. To date, no exploratory or confirmatory factor analyses have been conducted to study the factor structure of the Arabic version of the HESI. Therefore, the current study aimed to evaluate the psychometric properties of the Arabic version of the HESI (Arabic-HESI) among nursing students in Jordan.

Methods: The structure of the instrument was tested using exploratory factor analysis (EFA), confirmatory factor analysis (CFA), and maximum likelihood estimation among a sample of 355 nursing students at five Jordanian universities.
\end{abstract}

Results: The Arabic-HESI proved to have excellent content validity index $(\mathrm{CVI}=0.92)$. The instrument showed good internal consistency reliability (Cronbach's $a=0.75)$, as well as for the two emerged factors "challenges" and "dissatisfaction" (Cronbach's a were $0.75,0.72$ respectively). The results support the two-factor model for the Arabic$\mathrm{HESI}$, as the instrument was found to have robust structure and acceptable goodness-of-fit indices.

Conclusion: The Arabic-HESI is a reliable and valid instrument for assessing stress levels and stressors among nursing students in Jordan. Using the shortened version of the HESI to assess stress among nursing students is recommended. Identifying new features of stress and stressors among nursing students in Jordan will enable universities and nursing faculties to better support their students.

Keywords: Psychometric, Evaluation, Arabic, Higher education inventory scale, Nursing, Students, Jordan

\footnotetext{
* Correspondence: aahayajneh@just.edu.jo

${ }^{2}$ Adult Health-Nursing Department, Faculty of Nursing, Jordan University of

Science and Technology, P.O. Box: 3030, Irbid 22110, Jordan

Full list of author information is available at the end of the article
}

(C) The Author(s). 2021 Open Access This article is licensed under a Creative Commons Attribution 4.0 International License, which permits use, sharing, adaptation, distribution and reproduction in any medium or format, as long as you give appropriate credit to the original author(s) and the source, provide a link to the Creative Commons licence, and indicate if changes were made. The images or other third party material in this article are included in the article's Creative Commons licence, unless indicated otherwise in a credit line to the material. If material is not included in the article's Creative Commons licence and your intended use is not permitted by statutory regulation or exceeds the permitted use, you will need to obtain permission directly from the copyright holder. To view a copy of this licence, visit http://creativecommons.org/licenses/by/4.0/ The Creative Commons Public Domain Dedication waiver (http://creativecommons.org/publicdomain/zero/1.0/) applies to the data made available in this article, unless otherwise stated in a credit line to the data. 


\section{Background}

Stress is a natural physical, emotional, and mental reaction to a stimulus that disturbs the normal functioning of the body [1]. It is experienced when people recognize that the demands are greater than their individual and social resources [2]. Human beings respond to stress differently depending on their social, economic, environmental, and genetic backgrounds [3].

Nursing is considered a demanding and stressful profession due to the excessive workloads, complexity of patient care activities, unorganized work environments, and lack of leader support [4]. Similarly, healthcare education, including nursing education, is stressful for students, mainly due to the vast amounts and rates of knowledge and the frequent changes in needs and services [5]. Further, healthcare education does not focus only on teaching knowledge but also on teaching skills such as problem solving, research, interpersonal interaction, psychomotor, and lifelong learning skills $[5,6]$. This requires long hours of practical and theoretical study, which increases the pressure on students $[5,6]$. Previous studies have indicated that nursing students have higher stress levels compared to students of other healthcarerelated fields $[7,8]$, with education-related stress levels among nursing students ranging from medium to high [9-12]. While some stressors are considered motivational and may encourage achievement [13], experiencing prolonged stress threatens the physical, mental, and psychological health of students [6]. Furthermore, experiencing unresolved chronic stress may have adverse effects on students' academic performance [10, 14, 15]. Eventually, high levels of unresolved stress may discourage students from pursuing nursing education, therefore impacting the nursing workforce [10].

Studies in the literature have highlighted several education-related stressors among nursing students, including academic, clinical, and personal/social stressors $[9,15,16]$. Examples of academic stressors include heavy workloads, exams and assignments, the fear of failing and achieving low grades, and the lack of sufficient guidance from tutors [11, 17-19]. Clinical stressors include students' heavy responsibilities in clinical settings, students' uncertainty regarding what is expected from them, the pressure of meeting the expectations of staff, the fear of making mistakes and harming patients, and criticism from peers, senior staff, and physicians [11, 17, 19]. Personal and/or social stressors entail students' health issues, family events, lack of recreation time, high parental expectations, and financial issues [11, 17-19].

Previous studies have indicated a link between certain sociodemographic characteristics and increased stress levels among nursing students. For example, students from low-income families have been found to experience higher levels of stress in comparison to other students, as they may worry about not being able to meet their scholastic requirements, tuition fees, basic needs (i.e., food, accommodation, and transportation), or personal needs $[12,18,20]$. Further, with many universities now using blended learning and/or e-learning as a result of the COVID-19 pandemic, students from low-income families may worry about the costs of purchasing appropriate electronic devices, good internet services, and information applications [21]. Gender has also been found to impact students' stress levels, with female nursing students frequently reporting higher levels of stress compared to male students [12, 15, 20, 22]. Previous studies have attributed this to the fact that in comparison to female students, male students are more reluctant to talk about their stress experiences, are less aware of their stress, and have less knowledge about disease detection and health promotion behaviors [23, 24]. Male students may be less able to express their feelings due to cultural norms which associate masculinity with indomitability and power [15, 24]. As for the impact of academic year on students' stress levels, studies in the literature have reported conflicting findings. For example, Aslan and Akturk [22] and Ribeiro et al. [12] found stress levels to be higher among senior students than students in other years, mainly due to the nature of the advanced theoretical and clinical courses that senior students must take. Meanwhile, Admi and colleagues [14] found that junior nursing students experience the highest levels of stress, attributing this to their lack of knowledge and training experience required for future courses.

In Jordan, the wide spread of COVID-19, the strict national lockdown that was imposed by the government, and the transition to distance learning may have constituted new sources of stress for nursing students. In comparison to traditional education, distance learning is associated with higher stress levels among university students. The huge academic workload, the high frequency of examinations, and financial problems were sources of distance learning-related stress among university students in the study of Kwaah \& Essilfie [25]. Meanwhile, Moawad [26] concluded that the main stressors affecting university students as a result of the transition to distance learning during the pandemic were uncertainty regarding exams, the semester end date, and the evaluation methods used. Further, in the study of Cao et al. [27], financial difficulties, the changes caused to daily life, and the delays in academic activities were found to increase feelings of isolation and consequently anxiety levels among university students in China [27].

Identifying stress levels, sources of stress, and the impacting factors is crucial for creating effective measures that help nursing students adapt and improve their educational performance. Moreover, identifying the stress levels and stressors experienced by students 
enables nursing faculties and administrators to resolve the causes of stress, support students, and gain the trust of students $[19,22]$. Studies which have aimed to measure stress levels and sources among nursing students in Arab countries, including Jordan, are numerous [28-38]. However, all of these studies have used a single instrument which assesses clinical-related stress only and which was only recently psychometrically validated in the Arabic language [39]. Therefore, there is a need for a wider range of validated tools in order to ensure that various aspects of academic and clinical stress and stressors among nursing students in Arab countries are considered.

The Higher Education Stress Inventory (HESI) is a tool characterized by its ability to capture various aspects of stressors related to higher education regardless of the setting or the student population. The instrument was developed by a group of psychiatry professors in Sweden to measure stress among medical students [40]. It has previously been used to assess stress levels among medical students $[40,41]$ and distance learning students [42]. Although the language of instruction in all nursing schools in Jordan is English, the presence of a translated and validated instrument in Arabic (the official language of Jordan) would yield more accurate results and a better understanding of the context [39]. Considering the fact that stress levels and stressors vary depending on various sociocultural aspects $[43,44]$, the psychometric properties of the Arabic-HESI need to be evaluated using robust analyses like EFA and CFA. Therefore, the current study aimed to examine the psychometric properties of the Arabic-HESI, which is to be used to measure education-related stress among nursing students in Jordan, by applying EFA and CFA.

\section{Methods}

\section{Participants}

Three hundred and fifty-five undergraduate nursing students from five public universities located in the three regions of Jordan participated in the study. The majority of the participating students were from two universities in the North Region of Jordan (68.7\%), whilst $17.2 \%$ were from two other universities in the South Region, and the remaining $14.1 \%$ were from a university located in the Central Region. Students who were enrolled full-time in nursing programs and whose first language was Arabic were recruited, whilst students who had dropped out for the semester during which data were collected and students whose first language was not Arabic were excluded from the study. The mean age of the students was 20.02 years $(\mathrm{SD}=1.12), 72.7 \%$ of the students were female, and most of the students were in their second year of study (62.54\%). The sociodemographic characteristics of the students are displayed in Table 1.

\section{Procedure}

Google forms was used to create an online survey. After institutional review board approval from the authors' university was obtained and the facilitating requests from the other universities were granted, the survey was distributed to nursing students through the websites of the five universities. The participants were informed that their participation was voluntary and that they had the right to withdraw from the study at any time without consequences. Further, the contact details of the researchers were provided in case the participants had any questions. The survey included the HESI items in Arabic and questions about the participants' sociodemographic characteristics. Students who agreed to participate in the study were asked to complete the survey and click the "submit" button at the end.

\section{Measures}

The HESI was developed by Dahlin et al. [40] to measure higher education related stress among medical students. The inventory is neutral to educational settings, which allows for the comparison between different student populations. Four of the inventory items were borrowed and three of them were slightly modified from the Perceived Medical School Stress (PMSS) scale [45]. The inventory consists of 33 items which describe the presence and absence of stressful aspects in higher education. The items are scored on a 4-point Likert scale, where 1 = totally disagree, 2 = somewhat disagree, $3=$ somewhat agree, and $4=$ totally agree. The items $2,6,8$, $10,13,17,19,26,27$, and 33 are reversed items because they indicate the absence of stress. The original HESI factor analysis identified seven factors and included 24 items. The total variance explained by the factors was 48.7\%. The Cronbach's $\alpha$ was .85 for the instrument and was satisfactory for the seven factors as follow: worries about future endurance/competence $(\alpha=.78)$; nonsuppurative climate $(\alpha=.71)$; faculty shortcomings $(\alpha=.69)$; workload $(\alpha=.65)$; insufficient feedback $(\alpha=.65)$; low commitment ( $\alpha=.62)$; and financial concerns $(\alpha=.59)$.

Further, students were asked to answer an open-ended question about the sources of stress they had experienced as a result of the transition to distance learning during the COVID-19 pandemic. Questions regarding the students' sociodemographic characteristics and the circumstances of distance learning were also included in the survey.

\section{Translation}

After permission for use and translation was granted from the original author, the English version of the HESI was translated into Arabic by two independent bilingual nursing professors. One of the professors is specialized in psychiatry and the other in education, and both 
Table 1 Nursing students' sociodemographic characteristics

\begin{tabular}{|c|c|c|}
\hline Students' characteristics & $N$ & $\%$ \\
\hline \multicolumn{3}{|l|}{ Age $(M=20.02, S D=1.12)$} \\
\hline \multicolumn{3}{|l|}{ Gender } \\
\hline Male & 97 & 27.32 \\
\hline Female & 258 & 72.68 \\
\hline \multicolumn{3}{|l|}{ Family Monthly Income } \\
\hline Very low income & 222 & 62.54 \\
\hline Low income & 115 & 32.39 \\
\hline Medium to high income & 18 & 5.07 \\
\hline \multicolumn{3}{|l|}{ Academic year } \\
\hline First year & 60 & 16.90 \\
\hline Second year & 222 & 62.54 \\
\hline Third year & 41 & 11.55 \\
\hline Fourth year & 32 & 9.01 \\
\hline \multicolumn{3}{|l|}{ Number of courses enrolled in } \\
\hline Four courses & 55 & 15.49 \\
\hline Five courses & 169 & 47.61 \\
\hline Six courses & 90 & 25.35 \\
\hline Seven courses & 41 & 11.55 \\
\hline \multicolumn{3}{|l|}{ Clinical courses/Lab } \\
\hline Yes & 338 & 95.21 \\
\hline No & 17 & 4.89 \\
\hline \multicolumn{3}{|l|}{ Type of electronic device } \\
\hline Smart phone & 300 & 84.51 \\
\hline Other (Desktop Computer, laptop, tablet) & 55 & 15.49 \\
\hline \multicolumn{3}{|l|}{ Internet service type } \\
\hline Prepaid package & 215 & 60.56 \\
\hline Home internet with limited download & 82 & 23.10 \\
\hline Others (Home internet with unlimited download, Fiber,....) & 58 & 16.34 \\
\hline \multicolumn{3}{|l|}{ Is purchasing internet services a financial burden? } \\
\hline Yes & 299 & 84.23 \\
\hline No & 56 & 15.77 \\
\hline \multicolumn{3}{|l|}{ Do you have your own space to study at home? } \\
\hline Yes & 142 & 40 \\
\hline No & 213 & 60 \\
\hline
\end{tabular}

M Mean, SD Standard deviation

professors are fluent in both Arabic and English. Then, the HESI was back-translated into English by another professor specialized in translation. The two English versions of the HESI were then compared by a native speaker, showing no differences. The translated HESI was evaluated by 4 nursing experts who have experience in tools translation and validation. The researchers were asked to rate each instrument item on a 4-point Likert scale ranging from $1=$ "not relevant" to $4=$ "highly relevant". The content validity index (CVI) was 0.92 . The translated HESI was piloted on 15 nursing students from one of the five universities, and no significant issues were reported by the students.

\section{Statistical analysis}

Statistical analysis was performed using the Statistical Package for the Social Sciences (SPSS) version 25 (SPSS, Inc., Chicago, Ill) and Amos (Version 23.0) [Computer Program]. Chicago: IBM SPSS. The assumptions of normality, linearity, homogeneity, and homoscedasticity 
were checked for any violations. Reliability and validity analyses of the Arabic-HESI were performed by measuring the internal consistency reliability analysis (Cronbach's $\alpha$ ), exploratory factor analysis (EFA), and confirmatory factor analysis (CFA). EFA is the first step in validating a translated instrument that is to be used for the first time on a new population (i.e., Jordanian nursing students in the case of the current study) [46]. EFA was used to explore the underlying factor structure of the Arabic-HESI in order to examine the ability of the individual items to reflect stress. Preacher and $\mathrm{MacCal}-$ lum's guidelines [47] were used to conduct the EFA analyses. The CFA was performed using maximum likelihood estimation to confirm the EFA structure and investigate the goodness-of-fit indices of the yielded model. In order to examine the model's goodness-of-fit, a number of statistics were used: overall $X 2$, root mean square error of approximation (RMSEA) [48], comparative fit index (CFI), and the Tucker-Lewis index (TLI) [49]. CFA provides a theory-driven approach for establishing construct validity by assigning items to their corresponding factors based on theoretical beliefs [50].

The open-ended question was analyzed using content analysis [51]. The students' responses were reviewed separately by three researchers who are experts in qualitative research. The researchers then worked in collaboration to code and categorize the responses into themes. Descriptive analyses were used to describe the sample.

\section{Results}

\section{Reliability}

The HESI has never been translated into Arabic, nor has it been validated among Arab populations such as the Jordanian population. Therefore, the translated version needs to establish its psychometric properties in that new population [46]. Cronbach's alpha was used to examine the internal consistency of the Arabic-HESI. Any value above 0.7 is usually considered an acceptable reliability value for any given scale [52]. The Cronbach's alpha of the total score of the scale, which comprises 33 items, was 0.767. However, the inter-item correlation of these items was very low (0.095) (Table 2), raising questions regarding the dimensionality of the scale with these 33 items. As a result, exploratory factor analysis (EFA) was used to determine the number of underlying factors that these 33 items are loading on, and if some of these items are not loading adequately to be well-correlated

Table 2 Scale reliability statistics

\begin{tabular}{lllcc}
\hline & Mean & SD & Cronbach's a & Inter-Item correlation \\
\hline Scale & 2.568 & 0.590 & 0.767 & 0.095 \\
\hline $\begin{array}{l}\text { Of the observations, } \\
\text { were provided }\end{array}$
\end{tabular}

with their factors or subscales. The EFA is discussed in a separate section below. Iterated EFA results suggested the use of a two-factor model to reach the simple structure of the scale.

The EFA was used to explore the underlying factor structure of the original scale of the HESI based on Preacher and MacCallum's [47] guidelines. A parallel analysis suggested 9 factors, and the Kaiser method and scree plot suggested three factors (Fig. 1). Lastly, the dimensionality of the underlying theoretical framework of the original scale has never been demonstrated in the literature. Therefore, the EFA of the Arabic-HESI was carried out using three factors, as suggested by the Kaiser method and scree plot. A maximum likelihood examination with a Promax rotation was used due to the probability of a correlation between the factors, with 0.30 set as the cut-off point for factor loading [53]. Thirty-three items were tested using the EFA analysis, and the item loadings were yielded, as shown in Table 3.

As shown in Table 3, six items did not adequately load above 0.30 . These items were: "My studies control my life and I have little time for other activities", "The pace of the studies is too fast", "The studies have created anonymity and isolation among students", "I feel that the studies have played a role in creating a cold and impersonal attitude among students", "I feel that I am less well treated because of my sex", and "The training is characterized by an atmosphere where weakness and personal shortcomings are not accepted". Thus, these items were removed before re-running the EFA analysis. Then, the number of factors was reduced to two in order to achieve the simple structure of the EFA, which necessitates at least three items loading on the same factors. Then, after the EFA was repeated for the remaining items, 7 items did not load above 0.30 . These items were: "I meet many future colleagues that seem dejected or dissatisfied with their profession", "The teachers often give feedback on the students' knowledge and skills", "My fellow students support me", "I worry about the long working hours and responsibilities of my future career", "The studies stimulate my personal development", "The training demands that I join in situations that I find unethical", and "The insight I have gained into my future profession has made me worried about the stressful workload". These items were removed before re-running the EFA analysis, after which one item ("Student union activities promote a sense of community and contribute to a better working environment for students") did not load above 0.30. This item was then removed before re-running the EFA analysis for the remaining items. Lastly, the EFA simple structure of the two-factor model was achieved with 18 items, as shown in Table 3. Factor one had 14 items and was named "challenges", and factor two had 4 items and was named "dissatisfaction". 


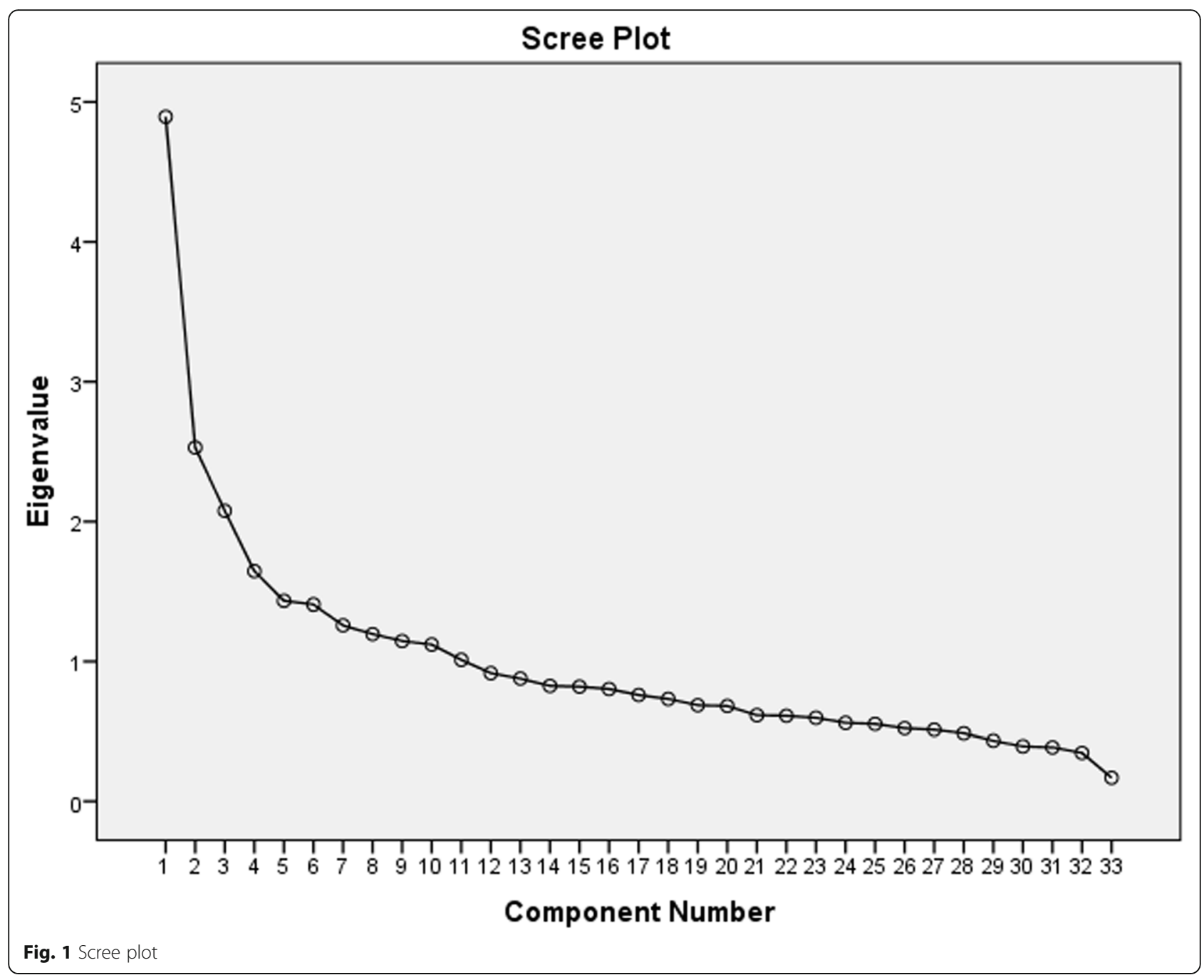

The two reliability values of factors one and two were 0.758 and 0.717 , respectively; as shown in Table 4, these values are considered good. After the removal of 17 items, as suggested by the iterated EFA, the final Arabic version of the HESI comprised 16 items (Table 5). The total scale reliability of the Arabic version of the HESI was 0.75 , which is considered good.

However, Table 5 of the item reliability statistics suggested that removing each of the items "There is a competitive attitude among students" and "I feel that the training is preparing me well for my future profession" would increase the Cronbach's alpha values of their subscales and factors from 0.686 to 0.758 , and from 0.659 to 0.717 , respectively. The two items were therefore removed, resulting in 13 items under factor one and 3 items under factor two. The total scale Cronbach's alpha value of the two-factor model of the Arabic version of the HESI was 0.75 (Table 5).

Confirmatory factor analysis (CFA) was conducted using the AMOS software based on a two-factor model, as suggested by the EFA (Fig. 2). All factor loadings of the latent variables displayed in Fig. 2 were above 0.3. In comparison to the three-factor model displayed in Table 3, the confirmatory factor analysis of the two-factor model showed a good fit, with the RMSEA (0.068) ranging between 0.058 and 0.078 . Also, the CFI and TLI were 0.841 and 0.803 , respectively, indicating an acceptable model and accounting for $45 \%$ of the total variance (Table 6). CFA incorporates the specification of one or more hypothesized models and each one proposes a group of factors (latent variables) to explain for covariance among a number of observed indicators. The latent factors are enclosed in the circle (dissatisfaction and challenges), the observed indicators (items) are enclosed in the rectangle, and the measurement error is enclosed in ellipses. Referring to Fig. 2 and Table 6, the model is determined by two interrelated constructs, challenges and dissatisfaction, which are connected with a double headed arrow indicating the correlation $(r=0.15)$. The one-headed arrow passing from the factor to the item is the regression path, which is the link between the factor 
Table 3 Exploratory factor analysis of the Arabic version of HESI, three-factor model, 33 items ( $N=355)$. Thirty-three items loadings of the Arabic version of HESI

\begin{tabular}{|c|c|c|c|c|}
\hline & $\begin{array}{l}\text { Factor } \\
1\end{array}$ & $\begin{array}{l}\text { Factor } \\
2\end{array}$ & $\begin{array}{l}\text { Factor } \\
3\end{array}$ & Uniqueness \\
\hline $\begin{array}{l}\text { Student union activities promote a sense of community and contribute to a better working environment } \\
\text { for students }\end{array}$ & . & 0.464 & . & 0.763 \\
\hline Studies control my life and I have little time for other activities & & . & & 0.958 \\
\hline The pace of studies is too high & . & . & . & 0.956 \\
\hline I am worried about accommodation & 0.460 & . & . & 0.777 \\
\hline There is a competitive attitude among students & . & 0.537 & . & 0.701 \\
\hline The studies have created anonymity and isolation among students & & . & & 0.827 \\
\hline I feel that the studies have played a role in creating a cold and impersonal attitude among students & . & & . & 0.895 \\
\hline I meet many future colleagues that seem dejected or dissatisfied in their profession & 0.335 & & & 0.849 \\
\hline The teachers give encouragement and personal attention & . & 0.517 & . & 0.667 \\
\hline I feel that I am less well treated because of my ethnic background & 0.365 & & & 0.829 \\
\hline The teachers often fail to clarify the aims of the studies & 0.380 & 0.400 & . & 0.612 \\
\hline The teachers often give feedback on the students' knowledge and skills & & 0.415 & & 0.797 \\
\hline My fellow students support me & . & 0.367 & . & 0.836 \\
\hline As a student, my financial situation is a worry & 0.431 & . & . & 0.784 \\
\hline I am worried about my future economy and my ability to repay student loans & 0.499 & & . & 0.742 \\
\hline I am able to influence the studies & . & . & 0.313 & 0.824 \\
\hline I feel that I am less well treated because of my sex & . & . & . & 0.926 \\
\hline The literature is too difficult and extensive & 0.424 & . & . & 0.796 \\
\hline I worry about long working hours and responsibilities in my future career & 0.349 & . & & 0.797 \\
\hline I am satisfied with my choice of career & 0.327 & . & & 0.810 \\
\hline I am worried that I will not acquire all the knowledge needed for my future profession & 0.422 & . & . & 0.750 \\
\hline The studies stimulate my personal development & & 0.426 & & 0.810 \\
\hline The professional role presented in the training conflicts with my personal views & . & 0.366 & . & 0.764 \\
\hline I am proud of my future profession & . & . & 0.787 & 0.348 \\
\hline As a student you are often expected to participate in situations where your role and function is unclear & 0.355 & . & . & 0.829 \\
\hline I am satisfied with my choice of career & . & . & 0.825 & 0.311 \\
\hline $\begin{array}{l}\text { There is too much focus on passive learning of facts and too little on active seeking of knowledge and } \\
\text { time for reflection }\end{array}$ & 0.357 & & & 0.836 \\
\hline I feel that my teachers treat me with respect & . & 0.416 & . & 0.699 \\
\hline The training demands that I join in situations that I find unethical & 0.339 & . & & 0.882 \\
\hline I feel that the training is preparing me well for my future profession & . & . & 0.313 & 0.813 \\
\hline $\begin{array}{l}\text { The training is characterized by an atmosphere where weakness and personal shortcomings are not } \\
\text { accepted }\end{array}$ & & . & & 0.914 \\
\hline $\begin{array}{l}\text { The education is highly characterized by group activities with unclear goals and with too much } \\
\text { responsibility placed on the student }\end{array}$ & 0.453 & . & & 0.813 \\
\hline The insight I have had into my future profession has made me worried about the stressful workload & 0.507 & & 0.326 & 0.640 \\
\hline
\end{tabular}

and its related items. This coefficient is the factor loading. The one-headed arrow from the ellipses to the rectangle is the measurement error.

The open-ended question revealed four themes related to the sources of stress among nursing students in relation to the transition to distance learning during the COVID-19 pandemic. The first theme was high unorganized workload, which encompassed complaints about the huge daily workload, the compressed delivery of the curriculum over a short period of time, and the overlap in online meeting times. The second theme, the lack of a uniformed distance learning strategy, included student complaints about the use of multiple learning methods and applications that were new to students and 
Table 4 The two factors model of the Arabic version of HESI

\begin{tabular}{|c|c|c|c|}
\hline & Challenges & Dissatisfaction & Uniqueness \\
\hline I am worried about accommodation & 0.484 & . & 0.783 \\
\hline There is a competitive attitude among students & 0.377 & . & 0.851 \\
\hline The teachers give encouragement and personal attention & 0.416 & . & 0.755 \\
\hline I feel that I am less well treated because of my ethnic background & 0.411 & & 0.841 \\
\hline The teachers often fail to clarify the aims of the studies & 0.574 & . & 0.654 \\
\hline As a student, my financial situation is a worry & 0.503 & . & 0.764 \\
\hline I am worried about my future economy and my ability to repay student loans & 0.530 & . & 0.738 \\
\hline I am able to influence the studies & . & 0.358 & 0.849 \\
\hline The literature is too difficult and extensive & 0.397 & & 0.830 \\
\hline I am worried that I will not acquire all the knowledge needed for my future profession & 0.488 & . & 0.780 \\
\hline The professional role presented in the training conflicts with my personal views & 0.446 & . & 0.790 \\
\hline I am proud of my future profession & . & 0.940 & 0.184 \\
\hline As a student you are often expected to participate in situations where your role and function is unclear & 0.370 & . & 0.856 \\
\hline I am satisfied with my choice of career & . & 0.859 & 0.320 \\
\hline $\begin{array}{l}\text { There is too much focus on passive learning of facts and too little on active seeking of knowledge and } \\
\text { time for reflection }\end{array}$ & 0.315 & . & 0.869 \\
\hline I feel that my teachers treat me with respect & 0.460 & . & 0.724 \\
\hline I feel that the training is preparing me well for my future profession & & 0.301 & 0.904 \\
\hline $\begin{array}{l}\text { The education is highly characterized by group activities with unclear goals and with too much } \\
\text { responsibility placed on the student }\end{array}$ & 0.337 & . & 0.895 \\
\hline
\end{tabular}

teachers, the use of unclear assessment methods, and the online delivery of clinical courses. The third identified theme was limited resources, including the limited financial and physical resources of the students. This theme also included the limitations in the technical infrastructure needed for the success of distance learning, whereby students complained about poor internet services and learning management systems. Distracting environment, which was the fourth and final theme, was related to the fear of COVID-19, the contradictory COVID-19-related news, and the noisy home environment.

\section{Discussion}

The stress experienced by nursing students in Jordan and in other Arab countries has been examined in many studies. However, to our knowledge, all studies that have been conducted in the Arab world have used a single instrument evaluating only clinical-related stress among nursing students. Although English is the language of instruction in Jordan, there are limitations in using nonArabic psychometrically evaluated instruments, due to language and cultural variations among students. Therefore, this study aimed to assess the psychometric properties of the Arabic version of the HESI. The translation of the HESI from English into Arabic has proved successful. This result is supported by the excellent CVI and the panel of experts' agreement that the items of the
Arabic-HESI adequately measured the sources of stress among nursing students [54].

The EFA yielded a two-factor model with 16 items reflecting different stressors perceived by nursing students in Jordan. A total of $45 \%$ of the variance was explained by the model, compared to the 24-item and 22item seven-factor models of the original and Korean versions, which explained 48.7 and $45.8 \%$ of the variance, respectively. The original HESI and the Korean HESI yielded seven factors, with variations in the items under the factors and in the significance of the factors to the construct of higher education [40, 44]. As for the Arabic-HESI, the items were grouped under two factors, namely "challenges and "dissatisfaction". The overall internal consistency of the Arabic-HESI was 0.75, compared to 0.85 for the original HESI and 0.78 for the Korean HESI. The Cronbach's alpha values for the subscales of the Arabic-HESI were higher in comparison to the factors of the original HESI, whilst they were close to the Cronbach's alpha values of most of the factors of the Korean HESI [40, 44]. This may be related to the variations in the number of items under each factor in the three versions.

According to the Cronbach's alpha results, the 13-item "challenges" factor was stronger than the 3-item "dissatisfaction" factor. The "challenges" factor items were grouped from 6 out of 7 factors of the original HESI, in addition to two other factors that were not loaded in any 
Table 5 Two factors model: item reliability statistics

\begin{tabular}{|c|c|c|c|c|}
\hline & M & SD & $\begin{array}{l}\text { Item-total } \\
\text { correlation }\end{array}$ & $\begin{array}{l}\text { If item } \\
\text { dropped } \\
\text { Cronbach's } \\
a\end{array}$ \\
\hline \multicolumn{5}{|l|}{ Factor 1: Challenges } \\
\hline C1: I am worried about accommodation & 2.172 & 1.128 & 0.399 & 0.654 \\
\hline Removed: There is a competitive attitude among students & 2.687 & 1.031 & 0.324 & 0.758 \\
\hline C2: The teachers give encouragement and personal attention & 2.546 & 0.911 & 0.319 & 0.667 \\
\hline C3: I feel that I am less well treated because of my ethnic background & 1.465 & 0.807 & 0.339 & 0.665 \\
\hline C4: The teachers often fail to clarify the aims of the studies & 3.028 & 0.809 & 0.452 & 0.651 \\
\hline C5: As a student, my financial situation is a worry & 3.127 & 0.929 & 0.412 & 0.654 \\
\hline C6: I am worried about my future economy and my ability to repay student loans & 2.501 & 1.103 & 0.442 & 0.647 \\
\hline C7: The literature is too difficult and extensive & 3.420 & 0.726 & 0.361 & 0.664 \\
\hline C8: I am worried that I will not acquire all the knowledge needed for my future profession & 3.569 & 0.699 & 0.373 & 0.663 \\
\hline C9: The professional role presented in the training conflicts with my personal views & 2.701 & 0.924 & 0.306 & 0.669 \\
\hline $\begin{array}{l}\text { C10: As a student you are often expected to participate in situations where your role and function is } \\
\text { unclear }\end{array}$ & 2.932 & 0.729 & 0.323 & 0.668 \\
\hline $\begin{array}{l}\text { C11: There is too much focus on passive learning of facts and too little on active seeking of knowledge } \\
\text { and time for reflection }\end{array}$ & 3.093 & 0.795 & 0.330 & 0.667 \\
\hline C12: I feel that my teachers treat me with respect & 1.775 & 0.802 & 0.423 & 0.655 \\
\hline $\begin{array}{l}\text { C13: The education is highly characterized by group activities with unclear goals and with too much } \\
\text { responsibility placed on the student }\end{array}$ & 2.969 & 0.878 & 0.304 & 0.670 \\
\hline Factor 1 (Cronbach's a after removal $=\mathbf{0 . 7 5 8})$ & 2.713 & 0.593 & & \\
\hline \multicolumn{5}{|l|}{ Factor 2: Dissatisfaction } \\
\hline S1: I am able to influence the studies & 1.901 & 0.826 & 0.314 & 0.673 \\
\hline S2: I am proud of my future profession & 1.420 & 0.760 & 0.651 & 0.454 \\
\hline S3: I am satisfied with my choice of career & 1.625 & 0.869 & 0.601 & 0.470 \\
\hline Removed: I feel that the training is preparing me well for my future profession & 1.828 & 0.864 & 0.252 & 0.717 \\
\hline Factor 2 (Cronbach's a after removal $=0.717)$ & 1.694 & 0.217 & & \\
\hline Total scale (Cronbach's a after removal $=0.75$ ) & & & & \\
\hline
\end{tabular}

of the 7 factors. This may be an indication of the comprehensiveness of the "challenges" factor. Although the "financial concerns" factor in the original HESI was the weakest, the items of this factor were grouped under the "challenges" factor in the Arabic-HESI. These items were more important in the Arabic-HESI due to the financial hardship experienced by many families in Jordan, as Jordan is a developing country $[18,55,56]$. In Jordan, about $84.9 \%$ of the population live below the poverty line [56]. Further, the indications of financial concerns for the participating students were clear. For example, about $95 \%$ of our sample came from low- and very low-income families, and more than $84 \%$ claimed that purchasing internet services in order to keep up with the requirements of distance learning constituted an additional financial burden. Also, the limited financial and physical resources of the students were indicated by the 'limited resources' theme that was identified from the students' responses to the open-ended question.
The "dissatisfaction" factor included the items of the "low commitment" factor from the original HESI and $50 \%$ of the items of the "low commitment" factor from the Korean HESI. The presence of these items emphasizes the importance of improving the educational environment in order to improve the experience and satisfaction levels of students, therefore reducing students' stress levels [14]. Aslan \& Akturk [22] and Hamaideh et al. [34] found that nursing students who choose nursing willingly and/or come to like it during their time in education experience lower stress levels than students who do not. Further, the items under the "dissatisfaction" factor highlighted the stereotypes about nursing held by some Jordanians. Despite the evolution of Jordanian society's view of nursing and nursing education over the past 70 years, some people in Jordan still do not consider nursing to be a prestigious major [57]. To the best of our knowledge, many students in Jordan do not choose to study nursing willingly; rather, for many 


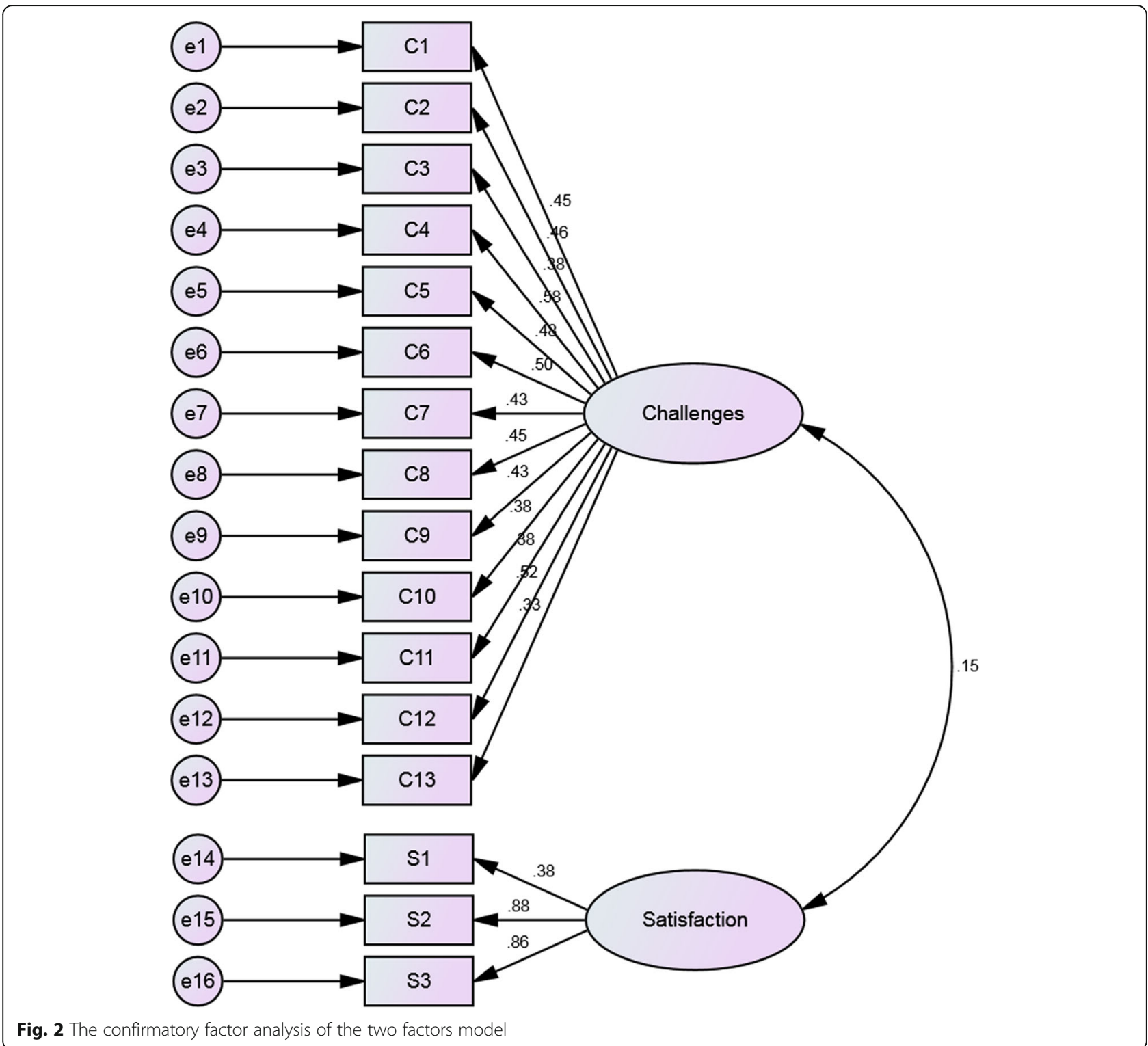

students, nursing is assigned to them by the unified admissions program based on their grades in the General Secondary Education Certification Examination (Tawjihi) $[58,59]$.

Items which present peer relationships as being a stressor, such as "The studies have created anonymity

Table 6 Goodness-of-fit statistics for two-factors model vs. three-factors model

\begin{tabular}{lll}
\hline Fit Statistics & Two-factors model & Three-factors model \\
\hline RMSEA (CI 90\%) & $0.068(0.058,0.078)$ & $0.068(0.062-0.74)$ \\
TLI & 0.803 & 0.698 \\
CFI & 0.841 & 0.726 \\
\hline
\end{tabular}

RMSEA Root mean square error, CFI Comparative fit index, TLI Tucker-Lewis index, $\mathrm{Cl}$ Confidence interval and isolation among students", "I feel that the studies have played a role in creating a cold and impersonal attitude among students", "My fellow students support me" (reversed item), and "There is a competitive attitude among students", were removed during analysis. Social support from peers has been found to decrease students' perceived stress during education [60], and in the context of Jordanian culture, relationships between students are characterized by strong and positive bonds [39]. Furthermore, items related to clinical training stressors, such as "The training is characterized by an atmosphere where weakness and personal shortcomings are not accepted", "The training demands that I join in situations that I find unethical", and "I feel that the training is preparing me well for my future profession", were also removed. This may be attributed to the fact that data 
collection took place during the period of transition to distance learning due to the COVID-19 pandemic, whereby practicum courses were taught that semester (second semester 2019/2020) using videos, computer simulations, and online quizzes and assignments. Students did not have the chance to practice in clinical settings and therefore did not experience the stressors related to actual training in clinical settings. However, the qualitative results revealed that nursing students had concerns regarding the termination of clinical training in actual clinical settings. Students were dissatisfied with the way that clinical courses were being delivered and felt that they were losing out on a golden opportunity to meet real patients and acquire psychomotor skills in real clinical settings.

Furthermore, the lack of training in clinical settings may have also reduced the students' perceived levels of stress regarding the stressors and responsibilities of their future profession. Therefore, the items "I meet many future colleagues who seem dejected or dissatisfied with their profession", "I worry about the long working hours and responsibilities of my future career", and "The insight I have gained into my future profession has made me worried about the stressful workload" were removed during analysis.

\section{Limitations}

This study is not without limitations. The crosssectional design of the study did not provide information about causal relationships among the variables. Also, the fact that this was a secondary data analysis hindered the researchers from examining the test-retest reliability, stability reliability, criterion-related validity, known-group validity, and convergent validity. Further, data were collected soon after the sudden and dramatic transition by all universities in Jordan to distance learning due to the COVID-19 pandemic. Despite the HESI being neutral to educational settings and student populations, we believe that the removal of many of the items in the ArabicHESI during analysis may have been due to this sudden transition. Therefore, using the Arabic-HESI in normal circumstances to verify the impact of the removal or redevelopment of the low-loading items on the complete HESI performance is recommended.

\section{Conclusion}

This study has provided initial evidence for the validity and reliability of the Arabic-HESI. The instrument showed good internal consistency reliability and excellent content validity. Using the reduced version of the HESI to assess stress among nursing students is recommended. In order to boost the results of the exploratory analysis of this study, future studies should use the Arabic-HESI on a larger sample size, during regular education, and using advanced confirmatory analysis. Identifying different aspects of stress and stressors among nursing students using a new instrument will enrich our knowledge and enable universities and nursing faculties in Jordan and the Arab world to use different strategies to create a new support system for students. These strategies will focus on the main sources of stress among this cohort of students and will be in line with Arab culture.

\section{Abbreviation}

HESI: Higher Education Inventory Scale

\section{Acknowledgements}

Thanks for Jordan University of Science and Technology.

\section{Authors' contributions}

We hereby confirm that all listed authors meet the authorship criteria and that all authors are in agreement with the content of the manuscript. Study conception \& design: DM; data collection and analysis: DM, AH; data interpretation: $\mathrm{DM}, \mathrm{AH}$; and manuscript preparation: $\mathrm{DM}, \mathrm{AH}, \mathrm{LT}$; final approval of the manuscript version to be published: DM.

\section{Funding}

This work was funded by the Jordan University of Science and Technology. [Grant number 20200316]. The University played no role in the study design, data collection, analysis, and interpretation, or the manuscript preparation.

Availability of data and materials

The raw data can be requested from the first author: Dina Masha'al, PhD, MSN, RN.

Ethics approval and consent to participate

The Institutional Review Boards of Jordan University of Science and Technology (IRB \#.20200316) and Consenting participants signed a written consent form

\section{Consent for publication}

Not Applicable.

\section{Competing interests}

All authors have no financial and non-financial competing interests.

\section{Author details}

${ }^{1}$ Adult Health Nursing Department, Faculty of Nursing, Jordan University of Science and Technology, P.O. Box: 3030, Irbid 22110, Jordan. ${ }^{2}$ Adult Health-Nursing Department, Faculty of Nursing, Jordan University of Science and Technology, P.O. Box: 3030, Irbid 22110, Jordan. ${ }^{3}$ Princess Salma Faculty of Nursing, Al-al-Bayt University, P.O. Box: 130049, Al-Mafraq 25113, Jordan.

Received: 14 August 2020 Accepted: 31 January 2021

Published online: 06 February 2021

\section{References}

1. American Institute. Stress effects. Available from https://www.stress.org/ stress-effects/. Accessed 30 July 2020.

2. Lazarus RS, Folkman S. Stress, appraisal, and coping. New York: Springer; 1984

3. Epel ES, Crosswell AD, Mayer SE, Prather AA, Slavich GM, Puterman E, Mendes WB. More than a feeling: a unified view of stress measurement for population science. Front Neuroenfocrin. 2018;49:146-69. https://doi.org/1 0.1016/j.yfrne.2018.03.001.

4. Alqahtani IM. Workplace stress among nurses. Int J Inn Res Med Sci. 2019; 4(12):690-3. https://doi.org/10.23958/ijirms/vol04-i12/802.

5. Jacob T, Itzchak EB, Raz O. Stress among healthcare students-a cross disciplinary perspective. Physiother Theory Pract. 2013;29(5):401-12. https:// doi.org/10.3109/09593985.2012.734011.

6. Labraque JL. Stress, stressors, and stress responses of student nurses in a government nursing school. Health Sci J. 2013;7(4):424-35 Available from 
http://www.hsj.gr/medicine/stress-stressors-and-stress-responses-of-studentnurses-in-a-government-nursing-school.pdf.

7. Beck D, Srivastava R. Perceived level and sources of stress in baccalaureate nursing students. J Nurs Educ. 1991;30(3):127-33.

8. Beck DL, Hackett MB, Srivastava R, McKim E, Rockwell B. Perceived level and sources of stress in university professional schools. J Nurs Educ. 1997;36(4):180-6.

9. Alzayyat A, Al-Gamal E. A review of the literature regarding stress among nursing students during their clinical education. Int Nurs Rev. 2014;61(3): 406-15. https://doi.org/10.1111/inr.12114.

10. Labrague LJ, McEnroe-Petitte DM, Gloe D, Thomas L, Papathanasiou IV, Tsaras K. A literature review on stress and coping strategies in nursing students. J Ment Health. 2017;26(5):471-80. https://doi.org/10.1080/0963823 7.2016.1244721.

11. Liu M, Gu K, Wong TKS, Luo MZ, Chan MY. Perceived stress among Macao nursing students in the clinical learning environment. Int I Nurs Sci. 2015; 2(2):128-33. https://doi.org/10.1016/j.jijnss.2015.04.013.

12. Ribeiro FMSES, Mussi FC, Pires CG d S, Silva RM d, Macedo TTS d, Santos CA d ST. Stress level among undergraduate nursing students related to the training phase and sociodemographic factors. Rev Lat Am Enfermagem. 2020;28:e3209. https://doi.org/10.1590/1518-8345.3036.3209.

13. Gibbons C. Stress, coping and burn-out in nursing students. Int I Nurs Stud. 2010;47(10):1299-309. https://doi.org/10.1016/j.jinurstu.2010.02.015.

14. Admi H, Moshe-Eilon Y, Sharon D, Mann M. Nursing students' stress and satisfaction in clinical practice along different stages: a cross-sectional study. Nurse Educ Today. 2018;68:86-92. https://doi.org/10.1016/j.nedt.2018.05.027.

15. Şentürk S, Doğan N. Determination of the stress experienced by nursing students' during nursing education. Int J Caring Sci. 2018;11(2):896-904.

16. Pulido-Martos M, Augusto-Landa JM, Lopez-Zafra E. Sources of stress in nursing students: a systematic review of quantitative studies. Int Nurs Rev. 2012:59(1):15-25. https://doi.org/10.1111/j.1466-7657.2011.00939.x.

17. Alghamdi S, Aljabri S, Jafari G, Alzebali R, Alkunaidiri N, Kalantan N. Sources of stress among undergraduate nursing students. Glob J Health Sci. 2019; 11(9):116. https://doi.org/10.5539/gjhs.v11n9p116.

18. Amanya SB, Nakitende J, Ngabirano TD. A cross-sectional study of stress and its sources among health professional students at Makerere University, Uganda. Nurs Open. 2018;5(1):70-6. https://doi.org/10.1002/nop2.113.

19. Parveen $\mathrm{A}$, Inayat $\mathrm{S}$. Evaluation of factors of stress among nursing students. Adv Pract Nurs. 2017;02(02):2-5. https://doi.org/10.4172/2573-0347.1000136.

20. Madian AAM, Abdelaziz MA, Ahmed HA. Level of stress and coping strategies among nursing students at Damanhour University, Egypt. Am J Nurs Res. 2019;7(5):684-96. https://doi.org/10.12691/ajnr-7-5-3.

21. Sowan AK, Jenkins LS. Designing, delivering and evaluating a distance learning nursing course responsive to students needs. Int J Med Inform. 2013;82(6):553-64. https://doi.org/10.1016/j.jimedinf.2013.02.004.

22. Aslan $\mathrm{H}$, Akturk U. Nursing education stress levels of nursing students and the associated factors. Ann Med Res. 2018;25(4):660. https://doi.org/10.54 55/annalsmedres.2018.06.108

23. Davies J, McCrae BP, Frank J, Dochnahl A, Pickering T, Harrison B, Zakrzewski M, Wilson K. Identifying male college students' perceived health needs, barriers to seeking help, and recommendations to help men adopt healthier lifestyles. J Am Coll Health. 2000;48(6):259-67. https://doi.org/10.1 080/07448480009596267.

24. Brougham RR, Zail CM, Mendoza CM, Miller JR. Stress, sex differences, and coping strategies among college students. Curr Psychol. 2009;28:85-97. https://doi.org/10.1007/s12144-009-9047-0.

25. Kwaah CY, Essilfie G. Stress and coping strategies among distance education students at the University of Cape Coast, Ghana. Turk Online J Distance Educ. 2017;18(3):120-34. https://doi.org/10.17718/tojde.328942.

26. Moawad RA. Online learning during the COVID- 19 pandemic and academic stress in university students. Revista Romaneasca Pentru Educatie Multidimensionala. 2020;12(1 Sup2):100-7. https://doi.org/10.18662/rrem/12.1 sup2/252.

27. Cao W, Fang Z, Hou G, Han M, Xu X, Dong J, Zheng J. The psychological impact of the COVID-19 epidemic on college students in China. Psychiatry Res. 2020;287:112934. https://doi.org/10.1016/j.psychres.2020.112934.

28. Aedh Al, Elfaki NK, Mohamed IA. Factors associated with stress among nursing students (Najran University - Saudi Arabia). IOSR-JNHS. 2015;4(6):338. https://doi.org/10.9790/1959-04663338.

29. Al-Gamal E, Alhosain A, Alsunaye K. Stress and coping strategies among Saudi nursing students during clinical education. Perspect Psychiatr Care. 2018;54(2):198-205. https://doi.org/10.1111/ppc.12223.
30. Shaban IA, Khater WA, Akhu-Zaheya LM. Undergraduate nursing students' stress sources and coping behaviours during their initial period of clinical training: a Jordanian perspective. Nurse Educ Pract. 2012;12(4):204-9. https://doi.org/10.1016/..nepr.2012.01.005.

31. Khater WA, Akhu-zaheya LM, Shaban IA. Sources of stress and coping behaviours in clinical practice among baccalaureate nursing students. Int J Humanit Soc Sci. 2014;4(6):194-202.

32. Akhu-Zaheya L, Shaban I, Khater W. Nursing students' perceived stress and influences in clinical performance. Int J Adv Nurs Stud. 2015;4(2):44. https:// doi.org/10.14419/ijans.v4i2.4311.

33. Al-Zayyat AS, Al-Gamal E. Perceived stress and coping strategies among Jordanian nursing students during clinical practice in psychiatric/mental health courses. Int J Ment Health Nurs. 2014;23(4):326-35. https://doi.org/1 $0.1111 /$ inm.12054

34. Hamaideh SH, Al-Omari H, Al-Modallal H. Nursing students' perceived stress and coping behaviors in clinical training in Saudi Arabia. J Ment Health. 2017:26(3):197-203. https://doi.org/10.3109/09638237.2016.1139067.

35. Alzayyat A, Al-Gamal E. Correlates of stress and coping among Jordanian nursing students during clinical practice in psychiatric/mental health course. Stress Health. 2016;32(4):304-12. https://doi.org/10.1002/smi.2606.

36. Mohamed BM, Ahmed ES. Perception of nursing students towards clinical stressors in the faculty of applied medical sciences-Al Jouf University-Saudia Arabia. J Am Sci. 2012;8(12):608-17.

37. Alsagri SH. Stressors and coping strategies of the Saudi nursing students in the clinical training: a cross-sectional study. Educ Res Int. 2017;2017:4018470 https://doi.org/10.1155/2017/4018470.

38. Ismaile S. Perceived clinical stressors among Saudi nursing students. Open J Nurs. 2017;7(04):463. https://doi.org/10.4236/ojn.2017.74036.

39. Algaralleh A, Altwalbeh $D$, Alzayyat A. Preliminary psychometric properties of the arabic version of sheu and colleagues perceived stress scale among nursing students at Jordanian universities. J Multidiscip Healthc. 2019;12: 777-87. https://doi.org/10.2147/JMDH.S214456.

40. Dahlin M, Joneborg N, Runeson B. Stress and depression among medical students: a cross-sectional study. Med Educ. 2005;39(6):594-604. https://doi. org/10.1111/j.1365-2929.2005.02176.x.

41. Dagistani A, Al Hejaili F, Binsalih S, Al Jahdali H, Al Sayyari A. Stress in medical students in a problem-based learning curriculum. Int J High Educ. 2016;5(3):12-7. https://doi.org/10.5430/ijhe.v5n3p12.

42. Hoang S. Stress among undergraduate distance learners: a cross-sectional study. PhD [dissertation]. Minneapolis: Walden University; 2016. Available from http://ovidsp.ovid.com/ovidweb.cgi?T=JS\&PAGE=reference\&D=psyc13 \&NEWS=N\&AN=2016-17133-056

43. Berman A, Snyder S. Kozier \& Erb's Fundammental of nursing concept process and practice. New Jersey: Pearson Prentice Hall; 2012.

44. Shim EJ, Jeon HJ, Kim H, Lee KM, Jung D, Noh HL, et al. Measuring stress in medical education: validation of the Korean version of the higher education stress inventory with medical students. BMC Med Educ. 2016;16(1):1-8. https://doi.org/10.1186/s12909-016-0824-9.

45. Vitaliano PP, Russo J, Carr JE, Heerwagen JH. Medical school pressures and their relationship to anxiety. J Nerv Ment Dis. 1984;172(12):730-6. https:// doi.org/10.1097/00005053-198412000-00006.

46. Hayajneh AA. The psychometric properties of the Arabic version of the Tilburg frailty indicator. Global J Health Sci. 2019;11(9):123-33. https://doi. org/10.5539/gjhs.v11n9p123.

47. Preacher, MacCallum. Repairing Tom Swift's electric factor analysis machine. Underst Stat. 2003;2(1):13 Available from: http://search.ebscohost.com/ login.aspx?direct=true\&db=bth\&AN=9228740\&site=ehost-live. Accessed 30 July 2020

48. Hooper D, Coughlan J, Mullen M. Structural equation modelling: guidelines for determining model fit. Electron J Bus Res Methods. 2008; 6:53-60.

49. Bentler PM. Comparative fit indexes in structural models. Psychol Bull. 1990; 107:238-46. https://doi.org/10.1037/0033-2909.107.2.238.

50. Strauss ME, Smith GT. Construct validity: advances in theory and methodology. Annu Rev Clin Psychol. 2009;5:1-25. https://doi.org/10.1146/a nnurev.clinpsy.032408.153639.

51. Hsieh HF, Shannon SE. Three approaches to qualitative content analysis. Qual Health Res. 2005;15(9):1277-88. https://doi.org/10.1177/10497323 05276687.

52. Kline P. A handbook of psychological testing. 2nd ed. London: Routledge: 1999. 
53. Al-Zaru IM, Hayajneh AA, Al-Dwaikat T. Psychometric properties of the Arabic version of the cardiac depression scale tested on Jordanian patients with cardiovascular diseases. BMC Psychiatry. 2020;20(1):246. https://doi. org/10.1186/s12888-020-02651-8.

54. Polit DF, Beck $C T$. Nursing research: generating and assessing evidence for nursing practice. New York: Lippincott Williams \& Wilkins; 2012.

55. Ali N, Jamil B, Sethi A, Ali S. Attitude of nursing students towards E-learning. Adv Health Prof Educ. 2016;2(1):24-9.

56. National Council of Family Affairs (NCFA). Jordanian family report. Jordan: NCFA; 2017. Available from http://ncfa.org.jo:85/NCFA/sites/default/files/ Publications/family-report.pdf

57. Zahran Z. Nurse education in Jordan: history and development. Int Nurs Rev. 2012:59(3):380-6. https://doi.org/10.1111/.1466-7657.2011.00947.x

58. Ahmad MM, Safadi RR. Entry criteria and nursing students' success. Jordan Med J. 2009:43(3):189-96.

59. Safadi RR, Saleh MYN, Nassar OS, Amre HM, Froelicher ES. Nursing students' perceptions of nursing: a descriptive study of four cohorts. Int Nurs Rev. 2011;58(4):420-7. https://doi.org/10.1111/j.1466-7657.2011.00897.x.

60. Hamdan-Mansour AM, Dawani HA. Social support and stress among university students in Jordan. Int J Ment Health Addict. 2008;6(3):442-50 https://doi.org/10.1007/s11469-007-9112-6.

\section{Publisher's Note}

Springer Nature remains neutral with regard to jurisdictional claims in published maps and institutional affiliations.

Ready to submit your research? Choose BMC and benefit from:

- fast, convenient online submission

- thorough peer review by experienced researchers in your field

- rapid publication on acceptance

- support for research data, including large and complex data types

- gold Open Access which fosters wider collaboration and increased citations

- maximum visibility for your research: over $100 \mathrm{M}$ website views per year

At $\mathrm{BMC}$, research is always in progress.

Learn more biomedcentral.com/submissions 